\title{
Anisotropic Avo Analysis for Reservoir Characterization in Derby Field Southeastern Niger Delta
}

\author{
*C.N. Ehirim and Chikezie N. O. \\ Geophysics Research Group, Department of Physics, University of Port Harcourt,P.O.Box 122, Choba, Port \\ Harcourt, Nigeria
}

\begin{abstract}
Anisotropic AVO analysis for reservoir characterization in Derby field southeastern Niger delta has been investigated. The objective of this study was to investigate the AVO response of shale over gas sandsonisotropic and anisotropic synthetic models and the real CDP gathers. This was done by plotting amplitude of reflections versus offsets and carrying out AVO intercept-gradient analysison HDIhorizon. The results of the models were compared with the real CDP gather to deduce the robust synthetic model for efficient AVO analysis in the field. Well, CDP processed gathers and Hampson-Russell GEOVIEW and AVO module were used for the analysis. Results revealed that the plots of amplitude versus offset of the isotropic and anisotropic synthetic models agree at near offset but show opposite AVO response due to increasing contributions of seismic anisotropy at far offsets. The results of the anisotropic synthetic model correlates well with the CDP gathers indicating that seismic anisotropy is an important factor in AVO analysis. Results also show that a bright spot indicative of gas charged sands was delineated for the isotropic and anisotropic models but with different classes of AVO anomalies andproducts. The isotropic synthetic model show a class II AVO anomaly with a positive AVO product, while the anisotropic model show a class IV AVO anomaly with a negative AVO product comparable to the real CDP gather.These analysesclearly show that description of rock without anisotropy especially, seismic anisotropy is incomplete since most rocks are not completely isotropic. Therefore, accounting for seismic anisotropy in AVO synthetic modelling will ensure that the correct earth model is predicted and the reservoir is adequately characterized.
\end{abstract}

Keywords:AVO, Isotropic synthetics, Anisotropic synthetics, seismic anisotropy

\section{Introduction}

Amplitude versus offset (AVO) analysis of prestack seismic data is a potentially powerful tool for hydrocarbon reservoir characterization (Castagna, 2000). The main thrust of AVO analysis is to obtain subsurface rock properties from reflection amplitudes and predict lithology and porefillusing surface seismic data (Ostrander 1984; Chiburis et al., 1993; Hilterman 2001; Thompsen, 2002; Veeken et al., 2002; Da Silva et al., 2004a).The amplitude character of seismic reflections varies with offset (or angle of incidence) and is largely controlled by lithology, porefill and anisotropy (Jenner, 2002, Li and Pickford, 2002). The contribution of anisotropy on reflection amplitudes is negligible at near offsets but at far offset, the effect becomes significant especially, when the overburden is anisotropic. Wave propagation through a weakly anisotropic or transverse isotropic medium is characterized by p- and s-wave velocities and Thompsen (1996) dimensionless anisotropic parameters $\varepsilon$ and $\sigma$ which determines the magnitude of the AVO response. Thompsen (1983) has shown that contrast in the anisotropic parameters across the interface controls the anisotropic AVO behaviour of a reflected p-wave at small and larger angles, respectively.

However, conventional AVO analysis is routinely based on linearized approximations to Zoeppritz's true plane wave reflection coefficients for isotropic elastic earth medium ( $\mathrm{Li}$, and Pickford, 2002). To the contrary, the earth is not isotropic, but rather anisotropic (i.e. weakly anisotropic) and because of this seismic wave propagates through the earth layers with a velocity that varies in different direction (Crampin et al 1984, Thomsen, 1986). It therefore follows that for a reliable and efficient characterization of the reservoir, seismic anisotropy of rocks must be accounted for in seismic modelling and interpretation of offset dependent seismic data.The offset (angular) dependence of p-wave reflection coefficients is expressed in terms of two parameters; the AVO intercept (A) and gradient (B) for angles of incidence less than $30^{\circ}$ (Castagna et al, 1998, Veeken and Rauch-Davies, 2006). Analysis of the intercept and gradient in cross plot domain and their products (AxB) in shale over gas sand horizons for Zoeppritz's plane wave isotropic and anisotropic synthetic models and the real seismic CDP gather could give indications of the effect of seismic anisotropy in AVO reservoir characterization in Ehi field (Fig. 1.0). 


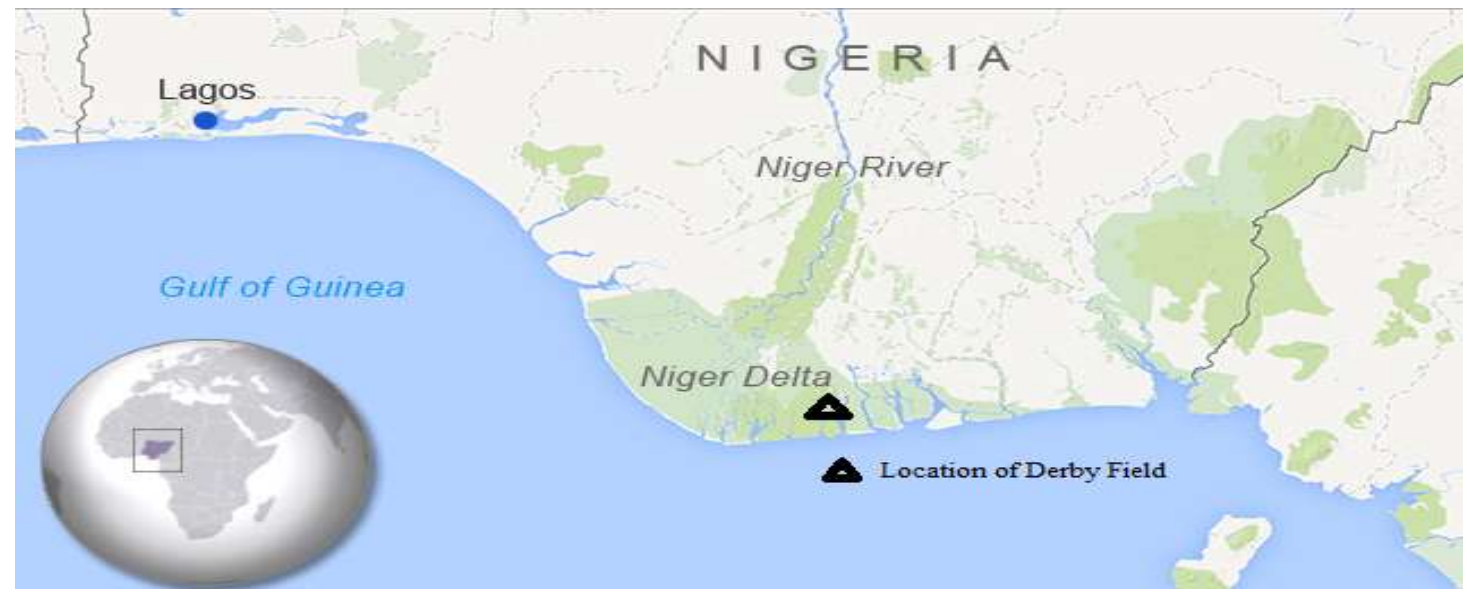

Fig. 1.0: Location map of the study area

This study is aimed at investigating the AVO response of shale over gas sands onisotropic and anisotropic synthetic models and the real CDP gathers. This was done by plotting amplitude of reflections versus offsets and carrying out horizon-based AVO intercept-gradient analysisof the synthetic models and real CDP gather. The results of the synthetic models will be compared with the real CDP gather to deduce the robust model for efficient AVO analysis in the field.

\section{Geology of the Study Area}

The Niger Delta is a sedimentary structure formed as a complex regressive offlap of clastic sediments ranging in thickness from $9000-12000 \mathrm{~m}$ (Avbovbo, 1978). Starting as separate depocentres, the Niger Delta has coalesced to form a single united system since Miocene. The Niger delta according to Short and Stauble (1967), is consist of three distinct lithofacies designated from bottom to top as Akata Formation, Agbada Formation, and Benin Formation (Fig. 2.0 ).

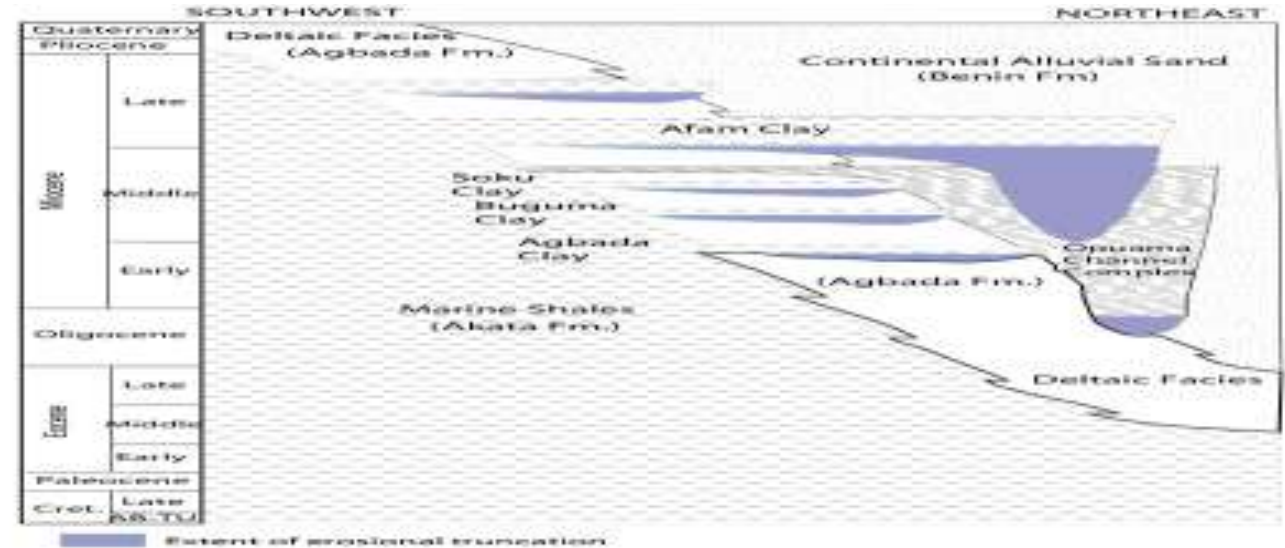

Fig. 2.0: Stratigraphic succession map of the Niger delta

The Akata Formation is the basal major time transgressive lithologic unit in the Niger delta complex. It is a marine prodeltamegafacies, comprising mainly of shales with occasional turbidite sandstones and siltstones and plant remains at the top. It is under-compacted (over-pressured) in much of the delta and is believed to have been deposited in front of advancing delta (Short and Stauble, 1967). The mature marine shales of the Akata Formation has been suggested to be the source rock of hydrocarbon in the Niger Delta (Doust and Omatsola, 1990).The Agbada Formation, which overlies the Akata Formation, is consists of paralic silicic clastics over 3,700 meters thick and divided into an upper unit consisting of sandstone - shale alternations with the former predominating over the latter and a lower unit in which the shales predominates. The sandy part constitutes the main hydrocarbon reservoirs and the shales form seals in the delta oil-fields (Ejedawe, 1981; Evamy et al., 1978Doust and Omatsola, 1990).The Benin Formation, on the other hand, has been described as "coastal plain sands". It consists mainly of sands and gravels with thicknesses ranging from 0 to 2100 metres (Avbovbo, 1978). The sands and sandstones are coarse to fine and commonly granular in texture and can be partly unconsolidated. The formation is generally water - bearing and the main source of potable groundwater in the Niger Delta area. 


\section{Method of Study}

3D pre-stack P-wave seismic data and well logs from Derby well were used for the analysis. The prestack 3D volume was processed into super gathers (often called common offset stack)in which each trace represents a range of offsets. These forms average CDPs to enhance the signal to noise ratio, while maintaining the AVOamplitudeinformationin the gathers (Fig.3.0).

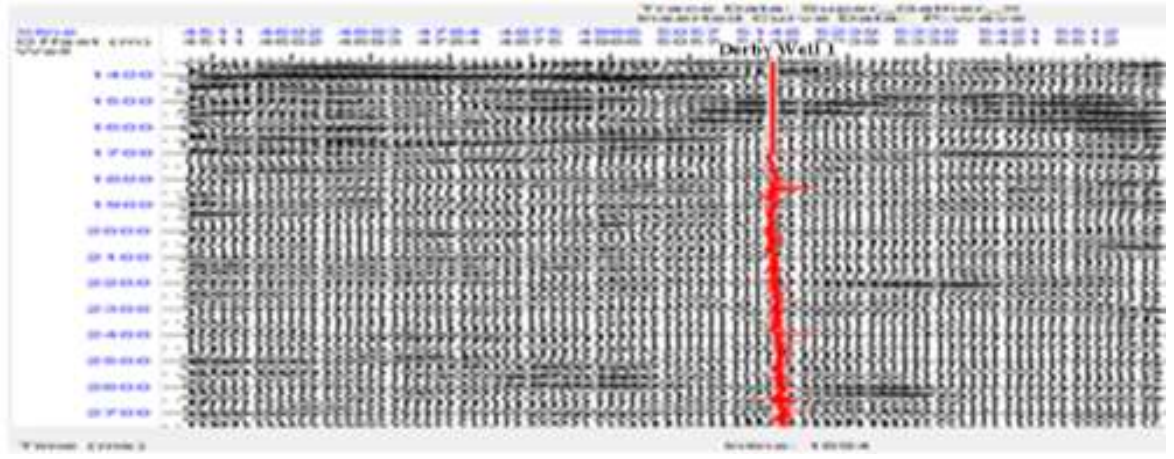

Fig. 3.0: 3D processed CDP Super Gather with inserted P-wave

The well logs consist of sonic log, gamma ray log, density log, true formation resistivity log, calliper $\log$, and check shot data. These logswere corrected for shale washout effects and de-spiked using median filter to remove high frequency noise and other borehole irregularities. Well log analysis was carried out and three prospective reservoir zones HDI, HDII and HDIII were delineated (Fig. 4.0). However, for the purpose of this study HDI reservoir only was used for anisotropic AVO analysis.

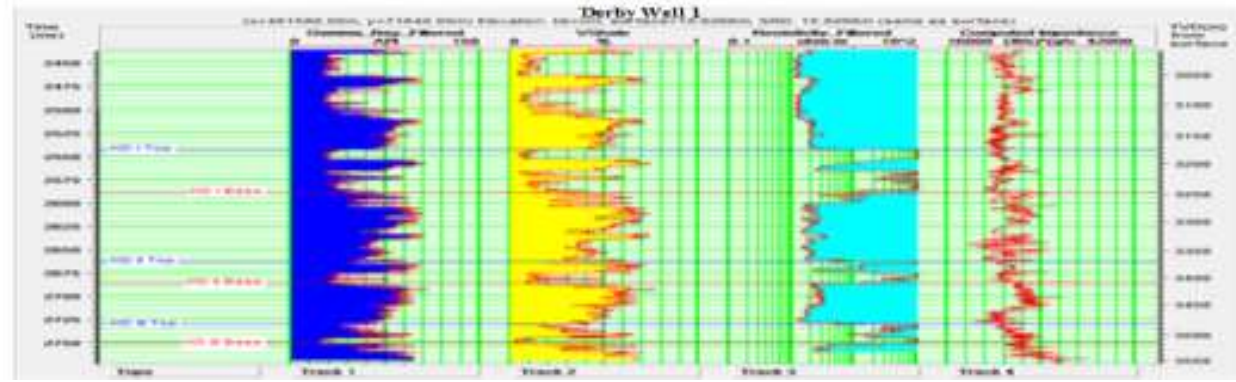

Fig. 4.0:Derby well showing suite of logs used in identifying prospective reservoirs

S-wave log was created using Castagna's mud rock relationship and modeled to the correct S-wave behaviour for gas sand by fluid substitution after rock physics analysis were carried outwithin the reservoir intervals.Thompson's anisotropy well logs (epsilon and delta) were created using the empirical relationship presented by $\mathrm{Li}$ (2002), from gamma ray log (Fig. 5.0).

Well $\log$ data was check shot corrected and correlated with the CDP gather (Fig. 6.0), and a statistical zero phase wavelet was extracted (Fig. 7.0).

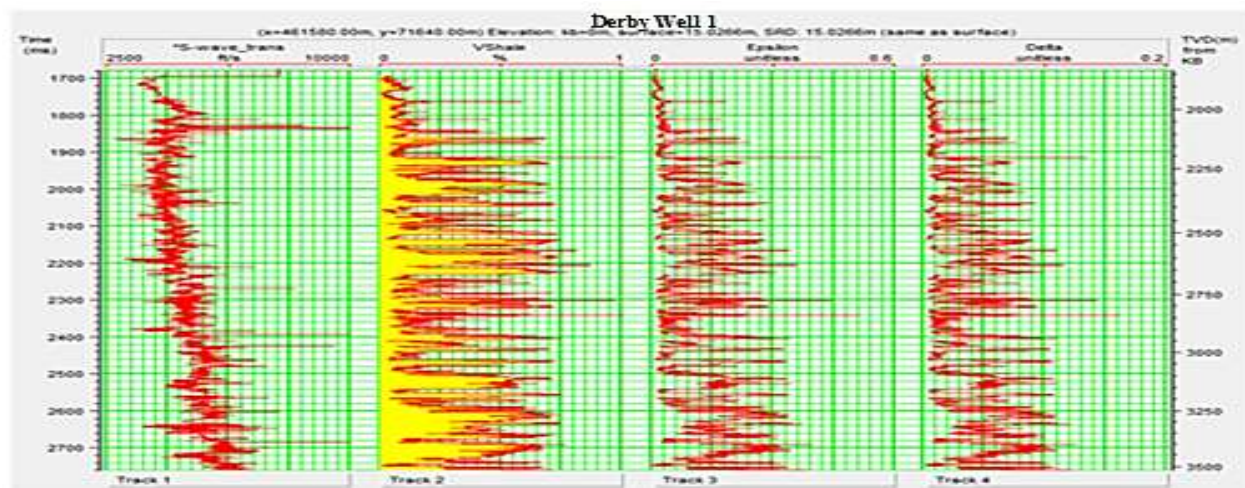

Fig. 5.0 : Computed S-wave, Thomsen Epsilon $(\varepsilon)$ and Delta $(\sigma) \log$ s for Ehi well 


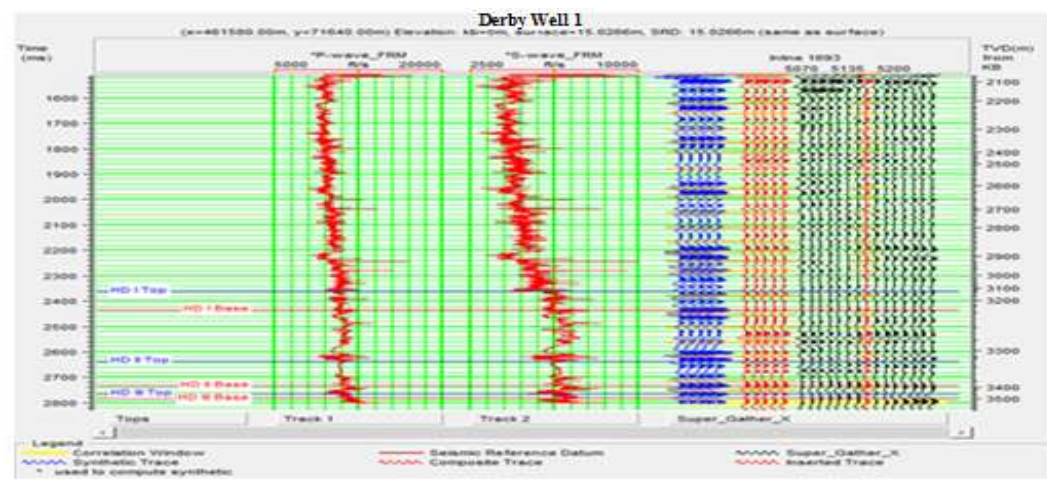

Fig. 6.0:Well log correlation window showing synthetic trace in blue, composite trace in red and CDP gather in black.

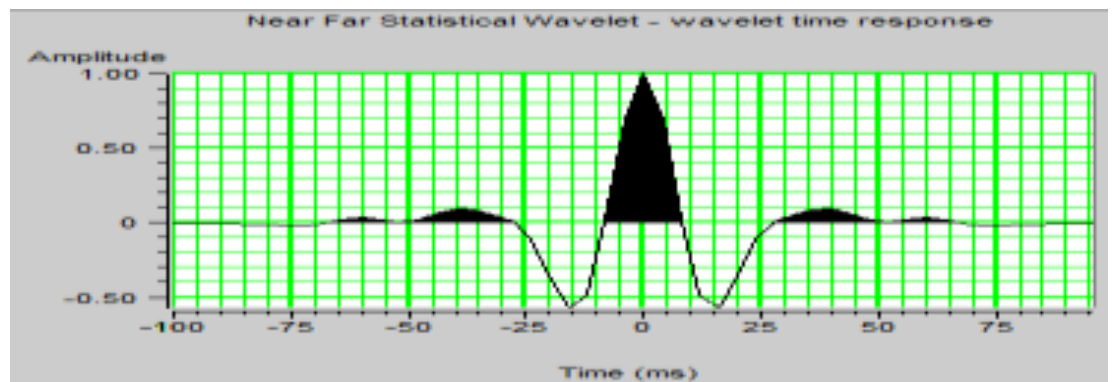

Fig. 7.0: The statistical extracted wavelet (zero phase) in time

Using Aki-Richards(1980) two term linearized approximations to Zoeppritz's p-wave reflection coefficients for an isotropic andtransversely isotropic media and incident angle less than $30^{\circ}$, isotropic and anisotropic AVO synthetic seismograms were generatedusing Hampson Russell AVO suit.Furthermore, to be able compare the synthetics withthe real CDP gather more quantitatively for anisotropic AVO analysis,amplitudes of the primary reflections were plotted against offsetand AVO intercept-gradient analysis was carried out on the generated synthetics and the real CDPgather on the HDI seismic horizon in the vicinity of Derby well location. Subsequently, the results of the synthetic models were compared with the real CDP gathers to deduce the robust model for mapping AVO anomalies in the field.

\section{Presentation of Results}

The results of the AVO analysis on HDI seismic horizon based on Aki-Richards two term approximation to Zoeppritz's equation for the isotropic, anisotropic and real CDP gather is shown in Figs. 8, 9 and 10, respectively. The seismicgathers to the top left (A) shows the HDI seismic horizon where the gradient analysis wasperformed marked by red line, while the plots on the top right (B) displays AVO curve of the reflector. The data points show the amplitudes from each trace whereas the solid line is adapted to the points to find the best fit AVO curve. The cross plot on the bottom right (C) shows AVO gradient versus intercept for the entire seismic time window. The plotted area is well focused around the reservoir and the highlighted point (in red) represents the plot at HDI horizon.
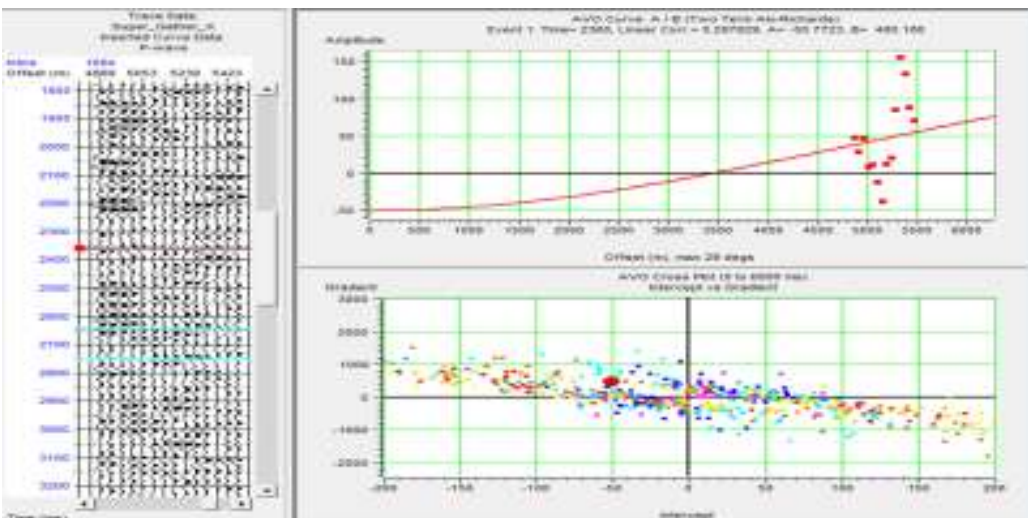

Fig. 8.0: AVO gradient analysis along HDI seismic horizon on the CDP gather 

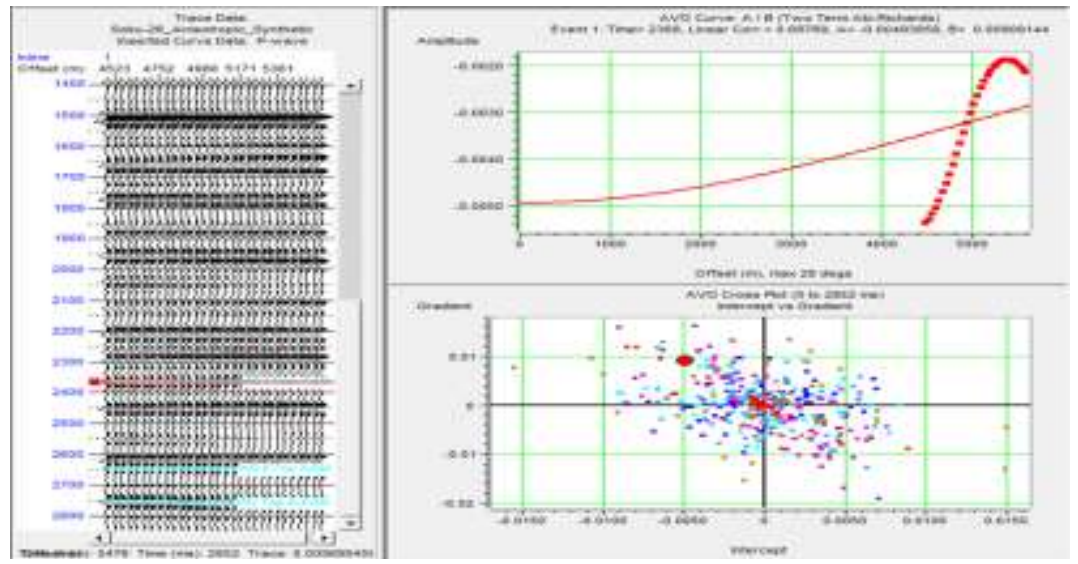

Fig. 9.0:AVO gradient analysis along HDI seismic horizon on the Anisotropic Synthetic Seismogram.

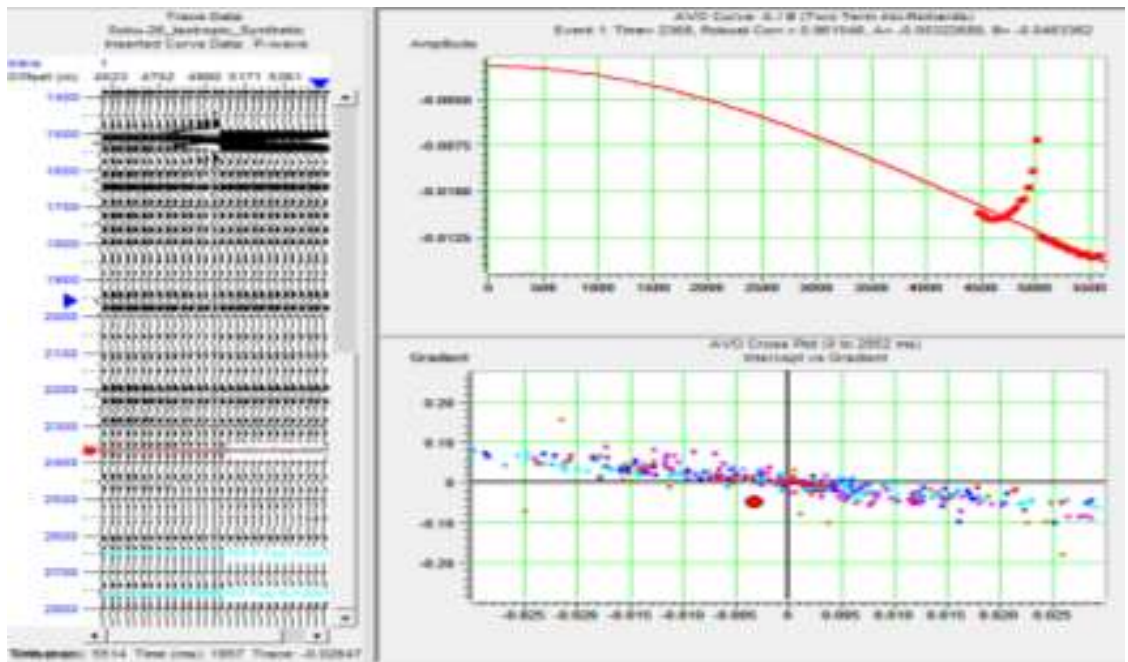

Fig.10.0: AVO gradient analysis along HDI seismic horizon on the Isotropic Synthetic Seismogram

These plots and their products wereanalyzedfor AVO anomalies (RutherfordandWilliams, 1989; Castagnaetal.,1998)and mappingof possible bright spots in the field.Result show that at near offsets, the isotropic and anisotropic models agrees but shows opposite AVO response with increasing offset.The isotropic synthetic model show decreasing amplitude with offsets in comparison to the increasing amplitude for the anisotropic model. However, the result of the anisotropic synthetic model agrees favorably well with the CDP gather, but the AVO effect on the CDP gathers appears to be small in comparison.Gradient analysis along the HDI seismic horizon on the CDP gather (Fig. 8.0), shows that the reflector (shale on gas sand boundary) has a relatively high negative intercept and weak positive gradient which fits well with a class IV AVO anomaly. This response is similar to the AVO gradient analysis for the anisotropic synthetic modelalong the same HDI horizon (Fig. 9.0), but with a relatively high positive gradient. The isotropic synthetic model however, show a weak negative intercept and gradient which fits well with a class II AVO anomaly for the same HDI seismic horizon (Fig. 10.0).Result also show that the CDP gather and the anisotropic synthetic seismogram have negative AVO product while the isotropic synthetic model has a positive AVO product. Thesummary of AVO gradient analysis and the products of their gradient and intercept values along HDI seismic horizon for the CDP gather, anisotropic and isotropic seismograms are shown in table 1.0.

Table 1.0: Summary of AVO gradient analysis and the product of their gradient and intercept along HDI horizon

\begin{tabular}{|l|l|l|l|l|l|l|}
\hline Seismogram & Interface & AVO Class & $\begin{array}{l}\text { Intercept } \\
(\mathbf{A})\end{array}$ & $\begin{array}{l}\text { Gradient } \\
(\mathbf{B})\end{array}$ & $\begin{array}{l}\text { Relative } \\
\text { Impedance }\end{array}$ & $\begin{array}{l}\text { AVO } \\
\left(\mathbf{A}^{*} \mathbf{B}\right)\end{array}$ \\
\hline CDP Gather & $\begin{array}{l}\text { Shale on } \\
\text { Sand }\end{array}$ & Class IV & -50.77 & 480.18 & $\begin{array}{l}\text { Low } \\
\text { Impedance }\end{array}$ & Negative \\
\hline $\begin{array}{l}\text { Anisotropic } \\
\text { Synthetic Model }\end{array}$ & $\begin{array}{l}\text { Shale on } \\
\text { Sand }\end{array}$ & Class IV & $-49.3 \times 10^{-}$ & $90 \times 10^{-4}$ & $\begin{array}{l}\text { Low } \\
\text { Impedance }\end{array}$ & Negative \\
\hline $\begin{array}{l}\text { Isotropic } \\
\text { Synthetic Model }\end{array}$ & $\begin{array}{l}\text { Shale on } \\
\text { Sand }\end{array}$ & Class II & $-32.3 \times 10^{-}$ & $\begin{array}{l}-46.3 \quad \mathrm{x} \\
10^{-3}\end{array}$ & $\begin{array}{l}\text { No or low } \\
\text { Impedance }\end{array}$ & Positive \\
\hline
\end{tabular}




\section{Discussion of Results}

AVO gradient analysis was carried out on isotropic and anisotropic synthetic seismograms generated from Aki-Richards (1980) two term linearized approximations to Zoeppritz's p-wave reflection coefficients for isotropic and transversely isotropic media and real CDP seismic gather. Result show that the reflection coefficient (amplitude) versus offset for the isotropic and anisotropic synthetic models at zero offset are negative and close to zero for both models, but shows opposite AVO response with increasingoffset. The isotropic synthetic model show decreasing amplitude with offsets in comparison to the increasing amplitude for the anisotropic model which matches the real CDP seismic gather. However, the amplitude increases for the anisotropic synthetic model is much larger than the CDP gathers and consequently, AVO effect on the gathers appear to be small in comparison.The fact that the results agree at near offset and differ at far offset is attributed to the increasing contribution of anisotropy to the AVO response with offset. For vertically transverse isotropic medium which is the simplest earth model, the Thompsen anisotropic parameters $\sigma$ and $\varepsilon$ affects AVO response of a p-wave reflection coefficient at intermediate offset (Gradient) and far offset (AVO curvature), respectively. The contrast in these anisotropic parameters across the interface controls the AVO response of a reflected p-wave comparable to the real CDP gather, but which differs from the isotropic case at larger offsets (Thompsen, 1993).

The result of the gradient analysis for the isotropic synthetic model along HDI seismic horizon show a weak negative intercept and gradient, which fit well with a class II AVO anomaly. This describes a moderately compacted sand that is less consolidated than class I sands, but more consolidated than class III sand with acoustic impedance of the encasing shale approximately equal to that of the gas sand(Rutherford andWilliams,1989; Castagnaetal.,1998). These sands will exhibit increasing AVO response and the reflections will become more negative with offset (bright spot). The result of the anisotropic synthetic model show relatively high negative intercept and positive gradient which fits well with a class IV AVO anomaly. This represents an unconsolidated saturated gas sand capped by high velocity or consolidated shale (Rutherford andWilliams, 1989; Castagnaetal., 1998). Consequently, these sands exhibit decreasing AVO response and may reverse polarity. In this case the reflections becomes more positive with offset (bright spot). This response is similar to the AVO gradient analysis of the CDP gather along HDI horizon but with a weak positive gradient (weak AVO effect). These results show that the anisotropic synthetic model correlate fairly well with the real CDP gather than the isotropic synthetic model. These results show that a bright spot indicative of gas charged sands was delineated for the isotropic and anisotropic models but with different classes of AVO anomalies. This shows that description of rock without anisotropy is incomplete since most rocks are not completely isotropic. Clearly, the inherent anisotropy of overburden shales on target horizons must be taken into account especially, for AVO analysis of hydrocarbon bearing reservoirs (Hornby et al, 1994). This will lead to a more correct model of the earth comparable to the real CDP seismic gather.

Results also show that the anisotropic synthetic model and CDP gather have negative AVO product while the isotropic synthetic model has a positive AVO product. These products are very helpful parameters for identifying clastic bright spot(Castagna et al, 1998). The positive AVO product associated with the anisotropic synthetic and real CDP gather is due to the negative AVO intercept and positive gradient arising from the low impedance contrast of the gas sands with the overlying shale. These contrasts with the negative AVO intercept and gradient (positive product) of the isotropic model due tono or lowimpedance contrast of the gas sands with the overlying shale.

\section{Conclusion}

Anisotropic AVO analysis in Derby field revealed that isotropic and anisotropic synthetic models agree at near offset but show opposite AVO response due to increasing contributions of seismic anisotropy at far offsets. The results of the anisotropic synthetic model correlates well with the CDP gathers indicating that seismic anisotropy is an important factor in AVO analysis. Seismic anisotropy causes p-wave velocities to vary with offset of propagation that causes AVO effect. Results show that a bright spot indicative of gas charged sands was delineated for the isotropic and anisotropic models but with different classes of AVO anomalies andproducts. The isotropic synthetic model show a class II AVO anomaly with a positive product, while the anisotropic model show a class IV AVO anomaly with a negative product comparable to the real CDP gather. The result of these analyses clearlyshow that description of rock without anisotropy especially, seismic anisotropy is incomplete since most rocks are not completely isotropic. Therefore, accounting for seismic anisotropy will ensure that the correct earth model is predicted and the reservoir is adequately characterized.

\section{References}

[1]. Aki, K. and Richards, P.G. (1980): Quantitative Seismology; Theory and Methods, V. 1: W.H., freeman and Co, P.557.

[2]. Avbovbo, A. A. (1978): Tertiary Lithostratigraphy of Niger Delta: American Association of Petroleum GeologistsBulletin, 62: 295300 .

[3]. Castagna, J.P. and Swan, J. (1997): Principles of AVO cross plotting. The Leading Edge 12, $337-342$. 
[4]. Castagna, J.P., Swan, H.W. and Foster, D.J. (1998): Framework for AVO Gradient and Intercept Interpretation; Geophysics, 63, $948-956$.

[5]. Castagna, J.P. (2000): AVO Analysis. CSEG Recorder, 26: (6), 47-70

[6]. Chiburis, E., Leaney, S., Skidmore, C., Franck, C. and McHugo, S. (1993): Hydrocarbon detection with AVO. Oil Field Review5, 42-50.

[7]. Crampin, S., Evans, R. and Atkinson, B.K. (1984): Earth quake prediction: a new physical basis, in proceedings of the first international workshop on seismic anisotropy, Suzdal, 1982, eds. S. Crampin, R.G. Hipkin and E.M. Chesnokov, Geophysical Journal of the royal astronomical Society, Vol. 78, Pg. 147-156

[8]. Da Silva, M., Rauch, M., Soto Cuervo, A. and Veeken, P.C.H. [2004a] Pre- and post-stack seismic attributes for enhancingproduction from the Cocuite gas reservoirs. 66th EAGE Conference, Paris, France, Extended Abstracts, D001

[9]. Doust, H., and Omatsola, E. (1990.) Niger Delta, in, Edwards, J. D., and Santogrossi, P.A., eds., Divergent/passive Margin Basins, AAPG Memoir 48: Tulsa, American Association of Petroleum Geologists, 239-248.

[10]. Ejedawe, J.E. (1981). Patterns of incidence of oil reserves in Niger Delta Basin: American Association of PetroleumGeologists, 65: 1574-1585.

[11]. Evamy BD, Herebourne J, Kameling P, Knap WA, Molley FA, Rowlands PH (1978). Hydrocarbon habitat of Tertiary Niger Delta. Am. Assoc. Petrol. Geol. Bull., 62: 1-39.

[12]. Hilterman, F. J. (2001): Seismic amplitude interpretation.SEG/EAGE short course no.4, Houston.

[13]. Hornby, B. E., Schwartz, L. M., and Hudson, J. A., (1994): Anisotropic effective-medium modelling of the elastic properties of shales: Geophysics, 59, 1570-1583.

[14]. Jenner, E. [2002] Azimuthal AVO: methodology and data examples. The Leading Edge 21, 782-786.

[15]. Li Y. (2002): Anisotropic well logs and their applications in seismic analysis, SEG Expanded Abstracts

[16]. Li, Y. and Pickford, S. (2002): Anisotropic well logs and their applications in seismic analysis. SEG Int'l Exposition and 72nd Annual Meeting.

[17]. Ostrander, W.J. (1984): Plane - Wave reflection Coefficients for gas sands at non- normal angles of incidence; Geophysics. 49 1637 -1648 .

[18]. Rutherford, S.R., and Williams, R.H. (1989): Amplitude versus Offset Variations in gas sands; Geophysics 54: 680 - 688.

[19]. Short KC, Stauble AJ (1967). Outline of Geology of Niger Delta. Am. Assoc. Pet. Geol. Bull. 51:761-799.

[20]. Thomsen, L. (1986): Weak Elastics Anisotropy: Geophysics, v. 51/10, p. 1954-1966.

[21]. Thomsen, L. (1993): Weak anisotropic reflections, in Castagna J. and M. Backus, eds., Offset dependent reflectivity, 103-114, SEG.

[22]. Thomsen, L. (2002): Understanding seismic anisotropy in exploration and exploitation: SEG/EAGE Distinguished Instructor Series.

[23]. Veeken, P.C.H and Rauch-Davies,M. (2006): AVO attribute analysis and seismic reservoir characterization. First Break Vol. 24 (2), Pg. 41-52 